\title{
Hybrid Olivine Phenocryst Populations in the 1959 Kîlauea Eruption and Constraints on Their Time of Arrival in the Summit Reservoir
}

\author{
Rosalind T. Helz ${ }^{1}$, Timothy R. Rose ${ }^{2}$ \\ 1US Geological Survey,rozhelz@gmail.com \\ ${ }^{2}$ Smithonian National Museum of Natural History, \\ roset@si.edu
}

Lavas of the 1959 summit eruption of Kîlauea Volcano contain 15.43 weight $\% \mathrm{MgO}$ on average. Continuous sampling during the eruption (14 Nov. -21 Dec.) found that samples with high $\mathrm{MgO}$ (16.5-19.5 wt. \%) were erupted either between 18-19 November or between 5-19 December. The November samples contain 20-25 wt. \% olivine in melt with 10 wt. $\% \mathrm{MgO}$. Olivine crystals in these and later phase 1 samples are unzoned or reversely zoned, while olivine in the later olivine-rich samples show normal zoning, consistent with progressive equilibration with shallower, stored magma. Thus the entire olivine load seems to have been delivered to the summit reservoir on 18-19 November.

The olivines are conspicuously heterogeneous: large, blocky deformed crystals and crystals with swarms of sulfidebearing melt inclusions, both antecrystic, make up $20-25 \%$ of the olivine load. The euhedral olivine phenocrysts $(>1 \mathrm{~mm}$ long) are chemically heterogeneous, consisting of $\sim 80 \%$ forsteritic olivine (Fo86.5-88.0) and 20\% of more Fe-rich olivine (Fo84-86). The latter compositions are expected for olivine crystallizing from the stored magma (melt $\mathrm{MgO}=8-9$ wt. \%). Subtracting these subpopulations from $20-25 \%$ bulk olivine leaves $15-16 \%$ olivine as potentially phenocrystic to the melts with $\mathrm{MgO}=10$ wt. \%.

Equilibrium crystallization calculations for bulk compositions with 11.5-12.2 wt. \% MgO (using MELTS) show that 3-4 wt. \% olivine will have crystallized at the point where melt $\mathrm{MgO}=10.0 \%$, and that the bulk olivine is $\sim$ Fo86. At higher bulk $\mathrm{MgO}$ contents, more olivine can crystallize: an initial melt with $14.5 \% \mathrm{MgO}$ would crystallize 7-8 wt. \% olivine when melt $\mathrm{MgO}=$ wt. $10 \%$. This is half the euhedral olivine that remains to be accounted for in the olivine-rich samples; thus even this subpopulation is derived from two or more melts.

Although the 1959 olivine population is varied, $\mathrm{CO}_{2}$ contents in melt inclusions are low and show little variation. Compositional mapping shows that simple euhedral olivine crystals have complex growth histories, with gradual infilling of forsteritic skeletal frameworks. The pervasive low $\mathrm{CO}_{2}$ contents suggest that sealing of melt inclusions is a late process, triggered by sudden undercooling of the high- $\mathrm{MgO}$ liquids when they first reached the summit reservoir. 